\title{
Consideraciones respecto de la protección constitucional y legal de los fondos privados de pensiones en el Perú ${ }^{*(* * *)}$
}

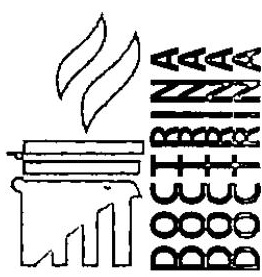

\author{
José Antonio Payet Puccio
}

Abogado por la Pontificia Universidad Católica del Perú. Master of Laws (LL.M.) por la Universidad de Harvard.

Profesor en la Universidad de Lima,

en la.Universidad Peruana de Ciencias Aplicadas, en la Escuela de Administración de Negocios para Graduados -

ESAN y en la Pontificia Universidad Católica del Perú.

Sheila La Serna Jordan

Abogada por la Pontificia Universidad Católica del Perú. Adjunta de Docencia en la Universidad Peruana de Ciencias Aplicadas.

SUMARIO:

I. Introducción.

II. El Proceso Argentino.

III. Capítulo 1: El derecho de propiedad:

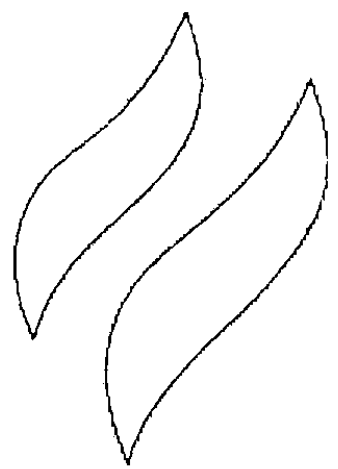

1. Fundamentos generales del derecho de propiedad;

2. Patrimonialidad de los fondos provisionales;

3. Causa o titulo de adquisición;

4. Uso, goce y disposición y limitaciones legales.

IV. Capitulo 2: Mecanismo para la protección de los fondos previsionales del SPP:

1. Mecanismos sustantivos de protección: la protección constitucional de los fondos provisionales;

2. Mecanismos procesales de protección:

2.1. Ordenamiento jurídico peruano;

2.2. Mecanismos de justicia internacional.

v. Capítulo 3: Análisis de derechos constitucionales que podrían ser afectados por una situación del tipo argentino.

VI. Capitulo 4: La expropiación indirecta y la protección de la propiedad en los tratados internacionales.

VII. Capítulo 5: Conclusiones y recomendaciones.

*) Los autores agradecen muy especialmente a la Asociación de AFP del Perú por la oportunidad de preparar este trabajo. 


\section{INTRODUCCIÓN}

A propósito de la reciente eliminación del régimen de capitalización individual privado de pensiones en Argentina, se nos plantea el reto de analizar desde la realidad peruana y sus instituciones, qué mecanismos prevé el ordenamiento jurídico peruano, y en particular la Constitución Política del Perú, para prevenir, y proteger a los fondos de pensiones de los trabajadores afiliados al Sistema Privado de Pensiones (SPP) de una medida de esa naturaleza.

Compartimos la idea de que la amenaza de medidas como la del caso argentino es parte del riesgo político al que están expuestos los sistemas de capitalización individual en países en vías de desarrollo.' El riesgo político afecta no solo la propiedad privada sobre los fondos de pensiones, sino también otros elementos del sistema económico, tales como, en general, la propiedad de los inversionistas y las empresas y la estabilidad del marco legal y regulatorio en el que operan. Sin embargo, considerando la gran masa de fondos que los sistemas de pensiones de capitalización acumulan en nuestros países, la tentación para un gobierno de recurrir a los recursos de los trabajadores afiliados a un sistema de capitalización individual para cubrir el déficit público, constituye un riesgo latente que, como nos enseña el caso argentino, puede no ser tan lejano a nuestras realidades.

De ahí que, en el marco de una crisis financiera mundial donde la tendencia es al intervencionismo y la publificación de la actividad empresarial $y$, en particular, del sistema financiero, resulta claramente pertinente evaluar la eficacia de las medidas constitucionales en materia pensionaria frente a la inestabilidad que podrían representan hoy en día las políticas públicas en esta área, pues detrás de ellas podrían esconderse verdaderas medidas de confiscación.
Mediante la Ley 26.425, se dispuso en la Argentina la unificación del Sistema Integrado de Pensiones en un único régimen provisional público denominado Sistema Integral Provisional Argentino (SIPA), a ser financiado a través del "sistema solidario de reparto". Esta unificación fue el medio para eliminar el régimen de capitalización y cuentas individuales, que fue absorbido por el régimen público. Como parte de la absorción, el artículo 7 de la referida ley establece lo siguiente:

"(...) transfiéranse en especie a la Administración Nacional de la Seguridad Social los recursos que integran las cuentas de capitalización individual de los afiliados y beneficiaros al régimen de capitalización del Sistema Integrado de Jubilaciones y Pensiones (...). Dichos activos pasarán a integrar el Fondo de Garantia de Sustentabilidad del Régimen Previsional Público de Reparto (...)".

Como contrapartida, los afiliados y pensionistas afectados por la privación de su ahorro previsional, reciben la promesa, contenida en la misma ley, de que "el Estado nacional garantiza a los afiliados y beneficiarios [del régimen de capitalización] la percepción de iguales o mejores prestaciones y beneficios que los que gozan a la fecha de entrada en vigencia de la presente ley". Nada se dice, sin embargo, de cómo se financiará el cumplimiento de esa promesa.

Con esta medida, justificada en la supuesta necesidad de "proteger los ahorros" de la crisis mundial, el Gobierno Argentino con la venia del Congreso habría confiscado los ahorros de 10 millones de trabajadores argentinos. ${ }^{2}$

Al respecto, resulta relevante mencionar que la Ley del SIPA fue la fase final de un proceso que se inició con medidas de expropiación indirecta de algunas inversiones en Argentina. Asi por ejemplo, se obligó a los fondos de pensiones a suscribir Letras del Tesoro. Al momento de

1 CORTAZAR, René, Interacciones entre el Sistema de Pensiones y el Sistema Politico. En: www.fiap.cl.

2 PIÑERA José, Barbarie en Argentina. En: Diario Financiero, Edición del 20 de Noviembre de 2008. 
vencimiento de los depósitos a plazo, se canjearon títulos públicos nacionales por préstamos garantizados y se pesificaron los instrumentos nominados en dólares a un peso y cuarenta centavos, al momento en que el tipo de cambio superaba al doble de dicho valor. ${ }^{3}$

En esta medida, el proceso culminó con la confiscación directa y expresa dispuesta por la Ley del SIPA, la cual ha sido calificada por un reconocido experto como "una opción por la barbarie yel subdesarrollo, que eliminó un sistema basado en la propiedad y el ahorro, y lo reemplazó por otro que depende de la caja fiscaly de la voluntad política del gobernante de turno".4

Resulta interesante notar que en el Perú, el ejemplo del SIPA argentino generó inmediatamente una preocupación legislativa por ampliar la protección de los fondos privados de pensiones. Al respecto, puede mencionarse el Proyecto de Ley $2817 / 2008-C R$ presentado por integrantes de la bancada del gobierno (Partido Aprista Peruano), el cual lejos de promover una medida como la adoptada en el caso argentino, buscó modificar ciertas disposiciones de la Constitución Política del Perú para reforzar la protección constitucional a los fondos privados de pensiones.

En este sentido, el tema que nos convoca y que será abordado en adelante es el siguiente: ¿qué mecanismos provee el ordenamiento jurídico peruano para proteger al SPP frente al riesgo político derivado de medidas como las adoptadas en Argentina?

Para estos efectos, será relevante analizar -fundamentalmente- las bases estructurales del sistema constitucional peruano en materia de propiedad y de seguridad social, así como los mecanismos procesales para su tutela efectiva.

\section{CAPÍTULO 1: EL DERECHO DE PROPIEDAD}

\section{Fundamentos Generales del Derecho de Propiedad}

El reconocimiento a la propiedad privada en un sistema legal tiene implicancias sustantivas en el régimen económico de un Estado, ya que resuelve un problema de acción colectiva: "Cuando algo no tiene dueño, nadie tiene incentivo para usarlo plenamente ni para protegerlo de la explotación. [El derecho de Propiedad] Asegura que las externalidades del uso serán internalizadas por las personas que están produciendo daños como beneficios sociales". ${ }^{5}$

Como puede verse, la asignación de la titularidad de la propiedad genera la exclusión de otros individuos del goce de un mismo bien. Ello genera incentivos para que los propietarios inviertan y ahorren, generando progreso económico en beneficio de la comunidad.

La Constitución Política del Perú de 1993, establece que el Perú es una República democrática, social, independiente y soberana y que "la iniciativa privada se ejerce en una economía social de mercado". En este contexto, el Artículo 2 , Inciso 14 , de la Constitución reconoce, con carácter de derecho fundamental, el derecho a la propiedad y la herencia. De esta forma se opta explícitamente por un régimen económico basado en propiedad y la competencia, si bien se admite la intervención estatal bajo ciertos límites y supuestos.

De acuerdo a las normas constitucionales antes citadas, siendo el régimen económico de la República del Perú el de una economía social de mercado, se protege el derecho de propiedad como una base fundamental de la organización del sistema económico.

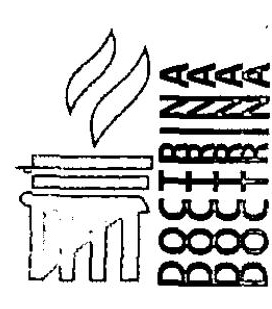

3 CORTAZAR, René, Op. Cit.

4 PIÑERA, José, Op. Cit.

5 SUNSTEIN, Cass R, Propiedad y Constitucionalismo. En: Revista de Derecho Themis, Edición No. 48, Editorial Impresso, Lima, 2004, p. 23. 


\section{Patrimonialidad de los fondos provisionales}

A fin de analizar cómo se vincula el derecho de propiedad y el derecho a la seguridad social, resulta pertinente resumir brevemente las $\mathrm{Ca}$ racterísticas principales del régimen del SPP, a fin de destacar fundamentalmente la relación jurídica del afiliado al SPP respecto de los fondos previsionales.

El régimen privado de pensiones peruano fue creado mediante Decreto Legislativo 724 en el año 1991. Esta norma, sin embargo, no tuvo aplicación en la práctica y el sistema fue "recreado" en el año 1992 mediante la entrada en vigencia del Decreto Ley 25897 bajo el cual las administradoras de fondos de pensiones (AFP) asumieron las prestaciones de jubilación, invalidez, sobrevivencia y gastos de sepelio de trabajadores los estatales y privados (dependientes e independientes) que optaran por dicho régimen.

Son tres las características básicas del SPP:

\section{(a) Administración Privada}

En el SPP la administración de fondos de pensiones se confía a entidades privadas denominadas "Administradoras Privadas de Fondos de Pensiones" en lugar del esquema centralizado característico del sistema público.

Según lo establece el Artículo 1 del Texto Único Ordenado de la Ley del SPP aprobado por Decreto Supremo No. 054-97-EF (la "Ley del SPP"), este sistema tiene como objetivo contribuir al desarrollo y fortalecimiento de la previsión social en el área de pensiones y está conformado por las AFP, las mismas que otorgan obligatoriamente a sus afiliados, las prestaciones de jubilación, invalidez, sobrevivencia y gastos de sepelio previstas en la referida norma. En el artículo 1 del Reglamento de la Ley del SPP, aprobado por Decreto Supremo No. 004-98-EF (el "Reglamen- to del TUO"), se establece que el SPP debe ser desarrollado por el sector privado.

Las AFP tienen objeto único y operan bajo estricta supervisión de la Superintendencia de Banca, Seguros y AFP (la "SBS"), la cual regula las operaciones e inversiones de los fondos de pensiones, con el objetivo primordial de preservar los intereses de los afiliados. La SBS autoriza a las AFP respecto de su constitución y su funcionamiento.

Cabe precisar que, tal como lo ha señalado el Tribunal Constitucional peruano respecto del SPP, "aun cuando la administración y las prestaciones de pensiones están en manos de agentes distintos del Estado, no por ese hecho este último deja de tener la condición de sujeto pasivo del Derecho a la Pensión y, en ese sentido, carece de obligaciones para con él". 6 Por ello, conforme al Tribunal Constitucional, "aún cuando las AFP son los nuevos responsables de la prestación exigida constitucionalmente, el principal obligado de asegurar el acceso a la prestación es el Estado", sea a través de una prestación directa en el sistema público; o a través de la supervisión de entidades privadas en el caso del SPP.

\section{(b) Libre competencia}

El SPP constituye un régimen de libre competencia entre las AFPs. Se trata de un mercado con pluralidad de proveedores y pluralidad de consumidores, donde no existen barreras de acceso significativas que impidan la entrada de nuevos actores al mercado y en el que, si bien el producto previsional se encuentra estrictamente regulado, las AFPs desarrollan libremente su oferta de servicios en el marco de la ley y la regulación vigentes y establecen libremente sus precios.

Adicionalmente, al lado del SPP se encuentra el Sistema Nacional de Pensiones (el "SNP"), administrado por la Oficina de Normalización Provisional (la "ONP"), el cual, si bien tiene una

6 Sentencia del Tribunal Constitucional recaída sobre el Expediente No. 1776-2004-AA/TC. 
naturaleza distinta que el sistema privado -es un régimen de administración estatal y de beneficio definido-y compite con este a través de la libre elección de todo trabajador al momento de incorporarse a la masa laboral. Más adelante volveremos sobre el tema de la libre elección entre sistemas.

En este punto no es nuestra intención extendernos en los beneficios que supone un régimen de libre competencia. Sin embargo, no resulta vano mencionar que la libre competencia en el mercado del SPP genera eficiencia en la medida en que, al encontrarse en competencia, las AFP tienen incentivos para reducir sus costos, incrementar la calidad y diversidad de sus productos o servicios y proveer a los consumidores con precios cercanos a su predisposición a pagar.

Actualmente, existen cuatro administradoras de fondos de pensiones (AFP) en régimen de competencia; AFP Horizonte; AFP Integra; Profuturo AFP y Prima AFP, quienes manejan las cuentas individuales de capitalización de aproximadamente $4^{\prime} 320,000$ de afiliados activos. ${ }^{7}$

\section{(c) Capitalización individualy propiedad privada sobre los Fondos}

A diferencia del SNP, el SPP funciona bajo la modalidad de cuentas individuales de capitalización ("CIC"), de manera.tal, que los afiliados a este sistema son propietarios de sus aportes $y$ de la rentabilidad que estos generan propiedad que se expresa a través de la $\mathrm{CIC}$, en la cual se registra el valor del ahorro previsional del afiliado, lo que le permite identificarlo en todo momento. La CIC se encuentra compuesta por los aportes del afiliado y las ganancias y rendimientos generados por la inversión de los fondos.

En la actualidad, cada trabajador puede elegir uno de tres fondos de pensiones para su $\mathrm{CIC}$ (bajo el denominado régimen de "multifondos"), en función de su edad y preferencia de riesgo, de conformidad con las normas aplicables.

Los aportes obligatorios de cada afiliado están constituidos por (i) el $10 \%$ de la remuneración asegurable del trabajador; (ii) un porcentaje de la remuneración asegurable destinado a financiar las prestaciones de invalidez y sobrevivencia y gastos de sepelio a cargo de compañías de seguros; $y$, (iii) los montos que cubren las AFP por la administración de los fondos.

\section{Causa o título de adquisición}

Mencionamos que el SPP se caracteriza por ser un sistema de propiedad y administración priva$\mathrm{da}$, se enmarca en un régimen de competencia. Además, debe destacarse que se soporta en la libertad de contratación del individuo.

Como el SPP es una alternativa al SNP, el trabajador tiene la posibilidad de elegir entre cualquiera de los dos regímenes existentes. Sin embargo, cotizar en alguno de ellos es de carácter mandatorio bajo ley peruana para todo trabajador dependiente, salvo para aquellos sujetos a un régimen pensionario privativo (tales como Fuerzas Armadas o Servicio Diplomático).

Por este motivo, si bien el trabajador puede afiliarse voluntariamente al SPP -ya que no se trata de una afiliación forzosa- sí está obligado a optar entre el SPP y el SNP. Al respecto, la normativa establece que se entenderá que la voluntad del individuo ha sido la de afiliarse al SPP, si el trabajador no comunica al empleador en el plazo de diez (10) días de iniciada la relación laboral su opción por el SNP. En este caso, el empleador lo afiliará a la AFP en que tenga más trabajadores afiliados.

Es importante destacar que la afiliación del trabajador a una AFP se realiza a través de la celebración de un contrato, lo que da lugar a

7 Boletín Semanal del Sistema Privado de Pensiones al 20 de febrero de 2009. Información disponible en la página web de la SBS: www.sbs.gob.pe . 
una relación jurídica de derecho privado. En tal sentido, el artículo 39 del Reglamento del TUO señala que "la relación entre la AFP y sus afiliados se rige por lo estipulado en los respectivos contratos de afiliación, que son contratos por adhesión, cuyos formatos deben ser aprobados previamente por la Superintendencia". El artículo 41 del Reglamento del TUO añade que si bien "la afiliación del trabajador queda perfeccionada con la suscripción del contrato de afiliación (...) todos los derechos y obligaciones correspondientes a su incorporación al SPP rigen desde el otorgamiento por la Superintendencia de un código de identificación que se denomina "Código Único de Identificación SPP'"'.

Para tener derecho a una pensión de jubilación bajo el SPP, debe contarse con sesenta y cinco (65) años de edad y haber efectuado aportes obligatorios, los cuales deben ser abonados mensualmente por los trabajadores dependientes a través de su empleador, quien actúa como agente retenedor; o de manera directa en caso de trabajadores independientes.

Sin perjuicio de ello, el afiliado puede jubilarse: (i) después de los sesenta y cinco (65) años, en cuyo caso se mantienen sus derechos y las obligaciones, como afiliado; $y$, (ii) anticipadamente, sujeto al cumplimiento de ciertos requisitos (que el afiliado obtenga una pensión igual o superior al $50 \%$ del promedio de las remuneraciones percibidas y rentas declaradas durante los últimos ciento veinte (120) meses, debidamente actualizadas).

\section{Uso, Goce y Disposición y limitaciones legales}

La propiedad clásica ha sido entendida como el derecho de usar de la cosa (ius utendi), percibir sus frutos (ius fruendi), y disponer de la cosa (ius abutendi). Así se reconocía desde el Code Napoleón al señalar que la propiedad es un derecho de gozar y disponer de las cosas de la forma más absoluta

De acuerdo a esta noción del concepto de propiedad, resulta evidente su carácter esencialmente individualista, ya que otorga un poder de decisión al individuo, respecto de las decisiones de los demás sobre la misma cosa. Sin embargo, ello no implica que el ejercicio del derecho de propiedad sea irrestricto, sino que se sujeta a los límites que señala la ley, por lo que el Estado puede limitar o condicionar el uso, goce o disposición de la propiedad en algunos casos.

En ese sentido, el artículo 70 de la Constitución protege el derecho de propiedad en los siguientes términos:

"Artículo 70. El derecho de propiedad es inviolable. El Estado lo garantiza. Se ejerce en armonía con el bien común y dentro de los limites de ley. A nadie puede privarse de su propiedad sino, exclusivamente, por causa de seguridad nacional o necesidad pública, declarada por ley, y previo pago en efectivo de indemnización justipreciada que incluya compensación por el eventual perjuicio. Hay acción ante el Poder Judicial para contestar el valor de la propiedad que el Estado haya señalado en el procedimiento expropiatorio".

En el caso de los fondos del SPP, hemos adelantado que el afiliado mantiene un derecho de propiedad sobre sus aportes y los rendimientos que de ellos se derivan. En tal sentido, entendemos que el ejercicio del derecho de propiedad respecto de los recursos del ahorro previsional que se derivan de la CIC, se manifiesta en la capacidad de exclusión de la que goza dicho afiliado al SPP: en la medida en que tales recursos son identificables en todo momento, se puede privar a otros del ejercicio de la titularidad de estos fondos.

Asimismo, el ejercicio de la propiedad del afiliado al SPP sobre los recursos provisionales del SPP se manifiesta también entre otros, en el poder de elegir el uso y disposición de los mismos, a saber: (i) cuál es la AFP que se encargará de gestionar tales inversiones para el financiamiento de su pensión de jubilación, incluyendo la posibilidad de cambiar de AFP o retornar al SNP con arreglo a ley; (II) qué tipos de fondo (Tipo 1 o Fondo de Preservación Patrimonial; Tipo 2 o Fondo Mixto; o Tipo 3 Fondo de Apreciación de Capital) se utilizará para generar el rendimiento esperado; y (iii) al momento del retiro, cuál es 
el destino final de los recursos previsionales acumulados en su $\mathrm{ClC}^{8}$, sea este la adquisición de una renta vitalicia o la permanencia de los fondos bajo la gestión de las AFP con posibilidad de efectuar retiros periódicos.

Finalmente, por ser de propiedad del afiliado, los fondos acumulados en la $\mathrm{CIC}$ no pueden ser objeto de privatización o confiscación.

Sin perjuicio de lo anterior, es evidente que el derecho de propiedad sobre los fondos previsionales de la $\mathrm{CIC}$ está sujeto a limitaciones legales derivadas de su propia naturaleza. En el Perú, conforme se desarrollará más adelante, los recursos de la seguridad social son considerados como intangibles, por lo que nadie puede utilizarlos ni disponer de ellos para fines distintos a aquellos para los que fueron creados. Esta limitación alcanza inclusive al afiliado activo, aún cuando fuera titular de la respectiva $\mathrm{CIC}$, en cuyo caso la restricción sobre la libre utilización y disposición de los recursos provisionales debe entenderse como temporal, hasta que cumpla los requisitos legales para acceder efectivamente a la pensión de jubilación.

\section{CAPITULO 2: MECANISMOS PARA LA PROTECCIÓN DE LOS FONDOS PREVISIONALES DEL SPP}

\section{Mecanismos Sustantivos de Protección: La Protección Constitucional de los Fondos Provisionales}

\section{(a) El Sistema de Fuentes}

En el Perú la materia pensionaria se encuentra prevista en la Constitución Política de 1993, y desarrollada fundamentalmente en normas con rango de ley y otras de rango reglamentario.

El sistema jurídico peruano también incluye a los tratados celebrados por el Estado, los que encontrándose en vigor, forman parte del derecho nacional. Como regla general, dichos tratados tienen rango de ley.
Sin perjuicio de lo anterior, debemos resaltar que, en virtud de lo dispuesto en el Artículo 51 de la Constitución Política de 1993, "la Constitución prevalece sobre toda norma legal; la ley, sobre las normas de inferior jerarquia, y asi sucesivamente. (...)". De acuerdo a ello, en caso de conflicto entre una norma constitucional y otra con rango de ley, la autoridad está obligada a aplicar la primera de ellas.

De otro lado, considerando que la jurisprudencia en el Perú también es fuente de derecho, debe tenerse en cuenta que el Tribunal Constitucional, como órgano de control de la Constitución, desarrolla criterios interpretativos con carácter vinculante para todos los poderes del Estado (en la medida que la sentencia del Tribunal Constitucional tenga la calidad de cosa juzgada y exprese que tiene tal carácter de precedente vinculante).

Además, que "las normas relativas a los derechos y a las libertades que la Constitución reconoce se interpretan de conformidad con la Declaración Universal de Derechos Humanos y con los tratados y acuerdos internacionales sobre las mismas materias ratificados por el Perú", según lo dispuesto en la Cuarta Disposición Final y Transitoria de la Constitución Política.

Hasta aquí nos hemos limitado a describir al sistema de fuentes del ordenamiento jurídico peruano en materia pensionaria. A continuación, nos referiremos en detalle al tratamiento del Derecho a la Seguridad Social, en particular, el Derecho a la Pensión, de conformidad con lo previsto en la Constitución Política.

(b) La seguridad social y las pensiones en la Constitución de 1993 y en la jurisprudencia del Tribunal Constitucional

Considerando que las normas constitucionales inspiran el ordenamiento legal peruano y priman sobre cualquier norma que se les oponga o las contravengan, nos referiremos en esta

8 Así se tienen diversos esquemas; renta vitalicia personal; renta vitalicia familiar; retiro programado o ciertas combinaciones de las anteriores.

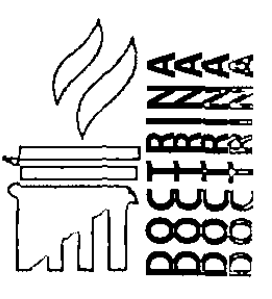


sección fundamentalmente a la protección sustantiva que otorga la Constitución Política del Perú de 1993.

Sobre el particular, debemos mencionar que la Constitución Política del Perú de 1993 contiene un desarrollo bastante desagregado de la seguridad social y, específicamente, en lo que nos interesa, de los derechos vinculados a la pensión, al acceso a una oferta plural de servicios previsionales. Asimismo, reconoce y desarrolla como derechos fundamentales el derecho de propiedad y el derecho a contratar libremente. ${ }^{9}$

Con relación al tratamiento constitucional del Derecho a la Pensión, la Constitución Política del Perú señala lo siguiente:

\section{El derecho a la seguridad social}

En primer lugar, el artículo 10 de la Constitución Politica del Perú establece que "El Estado reconoce el derecho universal y progresivo de toda persona a la seguridad social, para su protección frente a las contingencias que precise la ley y para la elevación de su calidad de vida".

En este sentido, son cuatro las características básicas que definen al Derecho a la Seguridad Social Pensión en el Perú desde el enfoque constitucional ${ }^{10}$ :

\section{(i) Es un derecho universal:}

La vocación de universalidad de este derecho reconocido a nivel constitucional tiene su base en la Declaración Universal de los Derechos
Humanos de $1948^{11}$ e implica que todos los ciudadanos (tanto trabajadores del sector público y privado, dependientes e independientes) tienen el derecho a acceder a la seguridad social.

\section{(ii) Es progresivo:}

Significa que el acceso a este derecho por cada integrante de la sociedad es gradual, lo que en términos prácticos implica que está delimitado por el tiempo y la situación económica de cada uno de los ciudadanos y el desarrollo de la economía nacional, entre otros factores.

\section{(iii) Otorga protección frente a contingencias que precise la ley:}

A diferencia de lo dispuesto en la Constitución Peruana de 1979 que enunciaba los riesgos cubiertos por la seguridad social, refiriéndose expresamente a "los riesgos de enfermedad, maternidad, invalidez, desempleo, accidente, vejez, muerte, viudez y cualquier otra contingencia susceptible de ser amparada conforme a ley", el texto constitucional vigente es "más realista" y no pretende cubrir todos los supuestos que pueden ser materia de la seguridad social, reservando a la ley su desarrollo.

\section{(iv) Procura la elevación del nivel de vida:}

Precisamente, el objetivo final del sistema de la seguridad social en el Perú es que las contingencias que se presenten en la vida de los ciudadanos que puedan limitar o restringir su capacidad para el trabajo no generen desmedros en su calidad de vida.

9 La Constitución del Perú contiene en el Capítulo I, Título I una lista de los "Derechos Fundamentales de la Persona", entre los cuales no se menciona expresamente el Derecho a la Pensión. Antes, se le considera como un derecho social y económico. Sin perjuicio de ello, el artículo 3 del Capítulo I, Título I precitado contiene una cláusula general que establece que "la enumeración de los derechos establecidos en el presente Capítulo no excluye a los demás que la Constitución garantiza", con lo cual se asegura la protección y tutela constitucional de ciertos derechos que no hubiesen sido incluidos de manera expresa en el catálogo de derechos fundamentales previsto en la Constitución, como sería el caso del Derecho a la Pensión.

10 ABANTO REVILLA, César y otros, La Constitución Comentada, Gaceta Juridica, Lima, 2006, pp. 419- 422.

11 Artículo 22.-Toda persona, como miembro de la sociedad, tiene derecho a la seguridad social, y a obtener, mediante el esfuerzo nacional y la cooperación internacional, habida cuenta de la organización y los recursos de cada Estado, la satisfacción de los derechos económicos, sociales y culturales, indispensables a su dignidad y al libre desarrollo de su personalidad. 
Cabe indicar que si bien puede existir una discusión teórica respecto de si el SPP tiene las características necesarias para considerarse como un régimen de seguridad social, en nuestra opinión en el caso peruano resulta claro que el Constituyente optó por una visión amplia de la seguridad social como un sistema conformado por una pluralidad de instituciones y mecanismos. De esta forma, si bien es posible que el SPP no reúna alguna de las características propias de "la" seguridad social, a nuestro criterio no cabe duda que es una parte del conjunto de instituciones y mecanismos previstos por el Constituyente para conformar el sistema integral de seguridad social del Perú.

\section{Pluralidad y libre acceso}

El artículo 11 de la Constitución Política del Perú establece que "El Estado garantiza el libre acceso a prestaciones de salud y a pensiones, a través de entidades públicas, privadas o mixtas. Supervisa asimismo su eficaz funcionamiento".

El texto constitucional vigente, planteó un cambio sustantivo con relación al texto constitucional anterior de 1979 que establecia un régimen centralizado de pensiones al indicar que sería una "institución autónoma y descentralizada, con personería de derecho público y fondos aportados por el Estado, trabajadores y empleadores, quien tiene a su cargo la seguridad social".

El texto constitucional vigente legitima la descentralización del sistema pensionario y la privatización del mismo. De acuerdo a ello, en el Perú coexiste el régimen el SNP a cargo de la ONP (creada en 1992 mediante el Decreto Ley 25967 como una institución pública descentralizada del Sector Economía) al lado del régimen del SPP conducido por las administradoras privadas de fondos de pensiones.

Esta disposición evidencia que en la configuración constitucional, la seguridad social en el Perú opera sobre la base de la pluralidad de instituciones y modelos; y privilegia la libertad del individuo. Téngase en cuenta que la Constitución vigente fue promulgada el 29 de diciembre de 1993, cuando estaba ya en funcionamiento el SPP. No es posible ignorar, en consecuencia, que cuando la Constitución se refiere a entidades privadas, comprende claramente a las AFP que operan el SPP.

Por ello, en el Perú, los trabajadores al momento de iniciar su actividad laboral, tienen la posibilidad de optar entre el SNP o el SPP. Asimismo, un trabajador afiliado al SNP puede traspasarse al SPP. Finalmente, un trabajador afiliado al SNP puede retornar al SNP si encuentra dentro de un supuesto de "libre desafiliación", conforme explicaremos más adelante.

\section{Intangibilidad de fondos y reservas}

En tercer lugar, el artículo 12 de la Constitución Política dispone que "Los fondos y las reservas de la seguridad social son intangibles. Los recursos se aplican en la forma y bajo la responsabilidad que señala la ley".

El primer punto que debe destacarse es que la Constitución Política se refiere a los "fondos y reservas de la seguridad social". Al respecto, se debe entender por "fondos" al conjunto de ingresos que estarían destinados exclusivamente para la atención de prestaciones. En lo que nos concierne, ello importa los fondos destinados al pago al pago o al financiamiento de pensiones.

En el caso de las "reservas", la referencia es a los montos constituidos para cubrir contingencias futuras según las proyecciones y estimaciones financieras que se efectúa para atenderlas, para lo cual se realiza cálculos actuariales, sobre la base de la estimación de diversos elementos tales como la evolución de recursos probables (ingresos), obligaciones (pensiones), número de asegurados, y plazo, considerando factores demográficos (como la PEA, tasa de desempleo); factores biométricos (tasa de natalidad y mortalidad, esperanza de vida); político sociales (plan de seguridad social estatal); entre otros. ${ }^{12}$

12 ABANTO REVILLA, César y otros, La Constitución Comentada, Gaceta Jurídica, Lima, 2006, p. 438. 
El concepto de intangibilidad fue desarrollado normativamente en el marco del Decreto Legislativo 817 mediante el cual se creó el Fondo Consolidado de Reservas Previsionales ("FCR"), como fondo para respaldar las obligaciones de los regímenes previsionales a cargo de la ONP. De conformidad con las normas reglamentarias del FCR (Decreto Supremo No. 144-96-EF), "los fondos y reservas provisionales que administra el FCR son intangibles, es decir que no pueden ser donados, embargados, rematados, dados en garantía, o destinados para un fin que no sea de carácter previsional" (el subrayado es nuestro).

La protección de intangibilidad prevista en la Constitución Política tiene como finalidad garantizar que los fondos y reservas destinados $a$ atender obligaciones pensionarias no sean indebidamente utilizados en objetivos distintos a aquellos para los cuales fueron creados, tanto a nivel del SNP como del SPP. No existe razón para distinguir respecto de la aplicación de esta garantía a los fondos del SPP respecto de los del sistema público. A nuestro criterio, habida cuenta del régimen plural de seguridad social previsto en la Constitución del Perú, no cabe duda de que tanto los fondos y reservas del SNP, como los fondos de pensiones que administran las AFPs, son "fondos y reservas de la seguridad social" $y$, en tal sentido, gozan de la intangibilidad que establece la Constitución.

Entendemos que, sin perjuicio de reiterar que su aplicación se da tanto en el sistema público como el sistema privado, entendemos que el telos de la norma constitucional -como cualquier otra garantía emanada de la Carta Magna- tiene como destinatario del mandato de intangibilidad fundamentalmente a los poderes del Estado, de manera tal que se eviten situaciones como aquellas ocurridas en el pasado con el Instituto Peruano de Seguridad Social (IPSS) (antes a cargo del SNP), en la cual el Gobierno"recurrió sistemáticamente a los fondos yreservas para atender la caja fiscaly para la realización de obras públicas".13

13 ABANTO REVILLA, César y otros, Op. Cit., p 438. 1999, p. 365.

\section{Propiedad y libertad de contratación}

Aún cuando no se refiere directamente a la materia pensionaria, hemos considerado en este análisis, destacar el reconocimiento constitucional al derecho a la propiedad privada y a la libertad de contratación previsto en la Constitución Política.

Como se ha visto con respecto a la propiedad, el artículo 2, inciso 16 de la Constitución Política, establece que "Toda persona tiene derecho a la propiedad y a la herencia". Asimismo, el artículo 70 de la Constitución Política consagra la inviolabilidad del derecho de propiedad, y señala además que "El Estado lo garantiza. Se ejerce en armonía con el bien común y dentro de los limites de ley. A nadie puede privarse de su propiedad sino, exclusivamente, por causa de seguridad nacional o necesidad pública, declarada por ley, y previo pago en efectivo de indemnización justipreciada que incluya compensación por el eventual perjuicio".

De las normas precitadas se desprende que la actual configuración constitucional de la propiedad es diferente a aquella prevista en la Constitución Política de 1979 que establecía que la propiedad debía encontrarse acorde con el interés social. Aún cuando la diferencia es sutil, el bien común puede ser entendido como la suma de intereses individuales ${ }^{14}$, lo cual tiene una connotación menos "socialista" y de "solidaridad".

Asimismo, como puede verse, la protección constitucional de la propiedad no es absoluta en la medida que la propia Constitución prevé la figura de la expropiación. Sin embargo, la Constitución Política establece un mecanismo legal para que el afectado en su derecho de propiedad tenga un debido procedimiento y en su caso, un derecho de indemnización que lo coloque en una situación por lo menos igual a aquella en la que se encontraba antes de ser expropiado. Por lo demás

14 RUBIO CORREA, Marcial, Estudio de la Constitución Politica del Perú de 1993, Tomo III, Fondo Editorial de la PUCP, Lima, 
parece difícil incluir un supuesto de "necesidad y utilidad pública" que justifique la expropiación de los fondos privados de pensiones.

Finalmente, debemos enfatizar que el concepto de derecho de propiedad constitucional tiene un efecto multiplicador ${ }^{15}$, lo cual quiere decir que el derecho de propiedad no solo se encuentra previsto en los artículos 2 y 70 de la Constitución antes comentados sino también comprende otros derechos e instituciones de rango constitucional. De esta manera, como verá más adelante, puede considerarse que la propiedad abarca incluso el derecho a una pensión.

La libertad de contratación está también reconocida y protegida como un derecho fundamental de la persona en la Constitución del Perú. En este sentido, el artículo 2, inciso 14 , de la Constitución reconoce el derecho de toda persona "a contratar con fines licitos, siempre que no se contravengan leyes de orden público". La "santidad" de los contratos ha sido desarrollada por el artículo 62 de la Constitución Política, que establece que "La libertad de contratar garantiza que las partes pueden pactar válidamente según las normas vigentes al tiempo del contrato. Los términos contractuales no pueden ser modificados por leyes $u$ otras disposiciones de cualquier clase". Entonces, de acuerdo con la garantía prevista en la Constitución Política los términos contractuales una vez acordados, no pueden ser modificados por normas posteriores de "cualquier clase". ${ }^{16}$ Como se ha visto anteriormente, siendo la relación afiliado-AFP de naturaleza contractual, el reconocimiento a la libertad de contratar constituye un mecanismo adicional de protección del SPP.

\section{La seguridad social en la jurisprudencia del Tribunal Constitucional}

Habiendo mencionado cuáles son las bases constitucionales que otorgan "blindaje" al SPP, conviene destacar ahora cómo ha interpretado el Tribunal Constitucional el concepto de seguridad social y, en particular, el Derecho a la Pensión.

Para estos efectos, resulta conveniente precisar que el Tribunal Constitucional se ha referido en numerosas sentencias -a través de una interpretación vinculante-, al Derecho a la Pensión como un "derecho fundamental de configuración legal" (Expediente No. 1417-2005-AA/TC, STC 0050-2004-Al, 051-2004-Al, 0004-2005-Al, 007-2005-Al acumulados), ya que requiere de la asistencia o intermediación de una ley para alcanzar plena concreción y ser materia de judicialización. ${ }^{17} \mathrm{~A}$ diferencia de otros derechos fundamentales que se derivan de normas de eficacia directa (autoaplicativas) como el derecho a la vida o el derecho a la salud, o el derecho de propiedad o a contratar con fines lícitos; y que son judicializables de manera inmediata, el derecho a la seguridad social y el Derecho a la Pensión reconocidos por la Constitución, requieren de un conjunto de "políticas sociales" para que el ciudadano pueda gozar de ellos y ejercitarlos de manera plena. ${ }^{18}$

El debate en torno al Derecho de Pensión también ha involucrado la discusión sobre si cuenta con "sustento constitucional directo", precisamente por su naturaleza de derecho programático o de eficacia diferida, por lo que se ha discutido sobre la posibilidad que el Derecho a

15 MEJORADA CHAUCA, Martín, La Acción de Amparo y el incumplimiento contractual, Publicado en el diario oficial El Peruano, el 2 de marzo de 1995.

16 Si bien doctrina autorizada ha interpretado que la intangibilidad de los contratos prevista en el artículo 62 de la Constitución solo incluiría a normas dispositivas (sobre las que cabe pacto en contra), y no así a las normas imperativas.

17 Este carácter programático o eficacia diferida del Derecho a la Pensión sería en realidad un lugar común para todos los derechos prestacionales (o derechos económicos y sociales como los denomina nuestra Constitución Política).

18 De ahi que la Undécima Disposición Transitoria y Final de la Constitución Política mencione que "Las disposiciones de la Constitución que exijan nuevos o mayores gastos públicos se aplican progresivamente". 
la Pensión sea susceptible de protección a través de un proceso constitucional como el proceso constitucional de amparo.

Sobre el particular, el artículo 38 del Código Procesal Constitucional que regula la procedencia de la pretensión de amparo señala que "No procede el amparo en defensa de un derecho que carece de sustento constitucional directo o que no esté referido a aspectos constitucionalmente protegidos del mismo".

En la sentencia recaída sobre el Expediente No. 1417-2005-AA/TC antes citada, el Tribunal Constitucional ha adoptado el criterio según el cual, la expresión "sustento constitucional directo" contenido en el artículo 38 del Código Procesal Constitucional "no se reduce a una tutela normativa del texto constitucional formal; por el contrario, se refiere a una protección material (pro homine) de la Constitución, en el que se integra la Norma Fundamental, con los Tratados de derechos humanos, tanto a nivel positivo, como a nivel interpretativo; y con las disposiciones legales que desarrollan directamente el contenido esencial de los derechos fundamentales que asi lo requieran". Tales disposiciones, afirma el Tribunal Constitucional en su sentencia, "forman el denominado canon de control constitucional o "bloque de constitucionalidad".

Asimismo, el Tribunal Constitucional concluye:

"(...) un derecho tiene sustento constitucional directo, cuando la Constitución ha reconocido, explicita o implícitamente, un marco de referencia que delimita nominalmente el bien jurídico susceptible de protección. Es decir, existe un baremo de delimitación de ese marco garantista, que transita desde la delimitación más abierta a la más precisa. Correspondiendo un mayoromenor desarrollo legislativo, en función de la opción legislativa de desarrollar derechos fundamentales establecidos por el constituyente".

Para el Tribunal Constitucional, el Derecho a la Pensión es sin duda un derecho fundamental cuyo contenido necesita una configuración o delimitación legal, es decir, que la ley culminará la delimitación concreta del contenido directa- mente atribuible al derecho fundamental, en atención a los límites o fronteras de los derechos, principios y valores constitucionales.

Cabe precisar que, para establecer reglas claras sobre cuál es límite de protección constitucional del Derecho a la Pensión, el Tribunal Constitucional ha definido el "contenido esencial" del derecho fundamental a la pensión como "núcleo duro" materia de protección constitucional, señalando que se encuentra conformado por (i) el derecho de libre acceso a una pensión; (ii) el derecho a no ser privado arbitrariamente de ella; $y$, (iii) el derecho a una pensión mínima vital.

De conformidad con el criterio expuesto, forman parte del contenido esencial directamente protegido: (i) las disposiciones legales que establecen los requisitos del libre acceso al sistema de seguridad social consustanciales a la actividad pública o privada, dependiente o independiente que permiten dar inicio al periodo de aportaciones; (ii) las disposiciones legales que establecen los requisitos para la obtención del Derecho a la Pensión; (iii) las pretensiones mediante las cuales se busque preservar un mínimo vital, lo cual se deriva de la estrecha relación del derecho fundamental a la pensiones con el derecho a la vida; $y$ (iv) las afectaciones al derecho a la igualdad material (en la aplicación de la ley), respecto de personas que se encuentran en idéntica o análoga situación y que no se encuentren basadas en causas razonables, proporcionales y objetivas.

\section{Mecanismos Procesales de Protección}

Habiendo analizado el contenido y "blindaje" constitucional del SPP y los derechos de los afiliados a este, corresponde revisar brevemente ahora, las instituciones procesales que hacen efectiva su tutela.

Si bien es cierto que los derechos que cuentan con sustento constitucional reconocidos por el Estado gozan de una tutela especial atribuible a su carácter fundamental, ello no basta para lograr su protección como bienes jurídicos, sino que, además, resulta imprescindible que el ordenamiento jurídico proporcione los mecanismos 
suficientes para tutelar dichos derechos ante un tercero imparcial e independiente que "diga derecho" con la finalidad de hacer efectiva su aplicación. En este sentido, nuestro ordenamiento tiene previstas por lo menos las siguientes vías para su exigibilidad ante el poder público:

\subsection{Ordenamiento Jurídico peruano}

\section{(a) Procesos de Defensa Constitucional:El Proceso de Inconstitucionalidad y el Proceso de Acción Popular}

El artículo 200, inciso 4, de la Constitución establece como garantía constitucional la Acción de Inconstitucionalidad. Esta "procede contra las normas que tienen rango de ley: leyes, decretos legislativos, decretos de urgencia, tratados, reglamentos del Congreso, normas regionales de carácter general y ordenanzas municipales que contravengan la Constitución en la forma o en el fondo. (...)". Asimismo, el artículo 200, inciso 5 de la Constitución establece como garantía constitucional la Acción Popular, que procede, por infracción de la Constitución y de la ley, contra los reglamentos, normas administrativas y resoluciones y decretos de carácter general, cualquiera sea la autoridad de la que emanen.

Tanto el Proceso de Inconstitucionalidad y el Proceso de Acción Popular tienen por finalidad la defensa de la Constitución por infracciones contra su jerarquía normativa, sea tal contravención directa o indirecta, por el fondo o por la forma.

Mientras que el proceso de acción popular puede ser iniciado por cualquier persona, el proceso de inconstitucionalidad solo puede ser promovido por un universo limitado de indivi- duos de la sociedad civil (cinco mil ciudadanos con firmas comprobadas por el Jurado Nacional de Elecciones; o los colegios profesionales en materias de su especialidad, adicionalmente por funcionarios públicos). ${ }^{19}$

Los efectos de la sentencia fundada recaída en el proceso de inconstitucionalidad y de acción popular tienen alcance general. En el caso del proceso de inconstitucionalidad, deja sin efecto la norma impugnada sin efecto retroactivo. ${ }^{20}$ En el caso de la acción popular se declara la nulidad con efecto retroactivo de la norma impugnada.

De acuerdo a lo anterior, toda norma con rango legal o reglamentario que contravenga las disposiciones constitucionales en materia pensionaria puede ser impugnada en la vía constitucional mediante los mecanismos ex post antes descritos.

\section{(b) Proceso de Tutela de Derechos Fundamentales: El Proceso Constitucional de Amparo}

El artículo 200, inciso 2, de la Constitución establece como garantía constitucional la Acción de Amparo. Esta "procede contra el hecho u omisión, por parte de cualquier autoridad, funcionario o persona, que vulnera o amenaza los demás derechos reconocidos por la Constitución, (...)". Cabe precisar que la Acción de Amparo, "No procede contra normas legales ${ }^{21}$ ni contra Resoluciones Judiciales emanadas de procedimiento regular".

En principio, el Proceso Constitucional de Amparo peruano tiene por finalidad tutelar de manera "urgente" aquellos casos en que se hubiera incurrido en una afectación directa de los derechos fundamentales, buscando por medio de este determinar si la afectación es de carácter incons-

19 Entre estos, el Presidente de la República, el Fiscal de la Nación, el Defensor del Pueblo, el veinticinco por ciento del número legal de congresistas, los presidentes regionales, etc.

20 Salvo en materia penal cuando favorece al reo y las normas tributarias dictadas en contravención a los principios de legalidad, reserva de ley, no confiscatoriedad, igualdad y respeto de los derechos fundamentales previstos en el artículo 74 de la Constitución Política del Perú.

21 Sin perjuicio de lo cual, el Código Procesal Constitucional Peruano que desarrolla el proceso constitucional de amparo faculta a utilizar este proceso contra actos basados en normas que violan los derechos fundamentales en ciertos supuestos. 
titucional y si incide sobre el ámbito directamente protegido por este derecho, a fin de "reponer las cosas al estado anterior a la violación del derecho constitucional, disponiendo el cumplimiento de un mandato legalo acto administrativo".

Existen derechos constitucionales -como el derecho a la propiedad o el de libertad de contratar-cuya protección a través del proceso constitucional de amparo resulta prácticamente inmediata y no requiere mayor explicación. En el caso de otros derechos constitucionales, como el Derecho a la Pensión, que tienen una naturaleza de derecho programático o de eficacia diferida y cuyo contenido debe ser delimitado legalmente, se requiere un análisis ulterior. $A$ tal efecto, el Tribunal Constitucional ha establecido las siguientes condiciones para la procedencia de la Acción de Amparo ${ }^{22}$ :

a) Que la pretensión sea válida, atribuible a una disposición constitucional que reconoce un derecho; $y$,

b) Que dicha pretensión válida se derive directamente del contenido esencial de un derecho protegido constitucionalmente $o$ guarde alguna relación con él.

Para establecer reglas claras sobre cuál es límite de protección constitucional del Derecho a la Pensión, el Tribunal Constitucional ha definido el "contenido esencial" del derecho fundamental a la pensión, indicando que se manifiesta concretamente en los escenarios descritos a continuación:

a) En caso se vulneren los requisitos del libre acceso al sistema de seguridad social que permitan dar inicio al periodo de aportaciones al Sistema Nacional de Pensiones. El Amparo procederá cuando el demandante hubiera cumplido con los requisitos legales necesarios pero se le niegue el acceso al sistema de seguridad social. b) Cuando se le niegue a una persona el reconocimiento de una pensión de jubilación, cesantía o invalidez, a pesar de haber cumplido los requisitos legales para obtenerla.

c) Aquellas pretensiones válidas mediante las que se busque preservar el monto de la pensión misma; concretamente, sobre el derecho a un "mínimo vital".

d) Supuestos en que se niegue el otorgamiento de una pensión de sobrevivencia a pesar de contar con los requisitos legales para obtenerla: casos de viudez, orfandad y pensiones de ascendientes.

e) Afectaciones al derecho a la igualdad como consecuencia de trato diferenciado a personas que se encuentren en condiciones similares al interior de un sistema pensionario. El derecho a la igualdad se verá afectado si se carece de bases razonables, proporcionales $y$ objetivas que justifiquen el tratamiento diferenciado.

Sin perjuicio de lo anteriormente señalado, debe tenerse en cuenta que el Código Procesal Constitucional establece que una demanda de amparo no puede rechazarse liminarmente (esto es, sin pronunciamiento sobre el fondo) en cualquier supuesto, sino solo cuando esta sea manifiestamente improcedente. Ello sigue la regla prevista en la doctrina, según la cual el principio de la tutela de urgencia se privilegia antes que el de competencia. Al respecto, Néstor Pedro Sagüés refiere que, por regla general, en caso de duda sobre la competencia de un magistrado, el juez requerido deberá conocer la acción, comentando que "los magistrados-dentro de 10 posible- deberán evitar cuestiones de competencia que atenten contra la celeridad del amparo y la pronta resolución de los problemas que se resuelven en dicha acción" ${ }^{\prime 23}$

Estas disposiciones tienen por objeto prevenir las lesiones que, bajo pretexto de incompeten-

22 Fundamentos contemplados en la Sentencia del Tribunal Constitucional recaida en el Expediente No. 1417-2005AA/TC, de fecha 8 de julio de 2005.

23 SAGÜÉS, Néstor Pedro, Derecho Procesal Constitucional. Acción de Amparo, Cuarta Edición, ASTREA, Buenos Aires, 1995, pp. $339-340$. 
cia, podrían generar un perjuicio irreparable al derecho constitucional en cuestión, y privilegian el carácter "urgente" de la tutela del amparo, en consideración de la naturaleza fundamental de los derechos afectados.

\section{(c) Protección Procesal Civil - Laboral - Administrativa}

Como regla general, todo afiliado que no se encuentre de acuerdo con algún aspecto derivado de la administración de su fondo de pensión por parte de la AFP, está facultado para presentar su reclamo por escrito a la AFP, siendo este derecho de naturaleza contractual (derivado del contrato de afiliación).

Asimismo, la controversia no resuelta de manera directa con la AFP puede ser sometida a conocimiento de la SBS, quien se pronunciará mediante decisión inapelable y con la que se dará por agotada la vía administrativa. En este caso dicha decisión podrá ser impugnada ante el Poder Judicial conforme a lo indicado en el literal (d) siguiente.

De otro lado, conviene precisar que la Ley del SPP provee de mecanismos procesales para la defensa del afiliado cuyos aportes no hubiera pagado el empleador. En dicho escenario, la AFP debe iniciar un proceso de ejecución para demandar la cobranza de adeudos provisionales en la vía judicial. Para estos efectos, la Ley del SPP impone en las AFP la carga de determinar el monto de los aportes adeudados por el empleador mediante una Liquidación para Cobranza, la cual constituye título ejecutivo.

\section{(d) Proceso Contencioso-Administrativo}

La Constitución Política establece que "Las resoluciones administrativas que causan estado son susceptibles de impugnación mediante la acción contencioso-administrativa."
En este sentido, el artículo 1 de Ley 27584, “Ley del Proceso-Contencioso Administrativo" (la $\underline{\mathrm{LP}(\mathrm{A})}$ establece que la finalidad de la acción contencioso administrativa es el control jurídico por el Poder Judicial de las actuaciones de la administración pública sujetas al derecho administrativo y la efectiva tutela de los derechos e intereses de los administrados.

Según las normas citadas, la LPCA faculta a cualquier ciudadano a solicitar ante el Poder Judicial la revisión en sede judicial de una decisión administrativa que le causare perjuicio, incluyendo decisiones en materia pensionaria. Al efecto, deberá cumplirse, entre otros requisitos con agotar la denominada vía previa. Esto implica que en principio, el afectado debe haber cumplido con interponer en sede administrativa los recursos que la legislación le provee para cuestionar la decisión que vulnera sus derechos. ${ }^{24}$

Sin embargo, mediante Decreto Legislativo 1067 de junio de 2008 , se modificó la LPCA, estableciéndose como excepción al agotamiento de la vía, el caso en el cual la pretensión planteada en la demanda esté referida al contenido esencial de la pensión, y haya sido denegada en la primera instancia administrativa.

Otro punto importante que debe resaltarse con relación al proceso contencioso-administrativo es que la interposición de este recurso no suspende la ejecución de la decisión administrativa del acto impugnado, sobre la base de la presunción de la legalidad del acto administrativo, salvo que el juez disponga la concesión de una medida cautelar.

Quizá a manera de paliar la situación antes descrita, y atendiendo al reconocimiento del Derecho a la Pensión como un derecho fundamental protegido constitucionalmente, la modificatoria a la LPCA ha diseñado un proceso especial denominado "proceso urgente", el cual

24 Así pues, mediante la pretensión contenciosa-administrativa, se busca (i) la declaración de nulidad, total o parcial o ineficacia de actos administrativos; (ii) el reconocimiento o restablecimiento del derecho o interés jurídicamente tutelado y la adopción de las medidas o actos necesarios para tales fines, (iii) la declaración de contraria a derecho y el cese de una actuación material que no se sustente en acto administrativo, (iv) se ordene a la Administración Pública la realización de una determinada actuación a la que se encuentre obligada por mandato de la ley o en virtud de acto administrativo firme; o (v) la indemnización por el daño causado. 
resulta aplicable, entre otros, a controversias en materia previsional en cuanto se refieran al contenido esencial del Derecho a la Pensión. Este procedimiento contiene plazos bastantes expeditivos para su resolución final. ${ }^{25}$

\section{(e) Protección Penal}

De acuerdo a la Ley del SPP, el trabajador, la AFP y/o la SBS pueden accionar penalmente por delito de apropiación ilícita contra los representantes legales del empleador, en el caso de que en forma maliciosa incumplan o cumplan defectuosamente con su obligación de pagar los aportes previsionales que hubieren retenido. Esta protección en la vía penal se otorga sin perjuicio de las sanciones administrativas, multas y moras que deban ser asumidas por el empleador por la demora o el incumplimiento de su obligación de retención y pago.

En esta medida, si el empleador retiene el monto correspondiente a la aportación obligatoria al afiliado y no paga en el plazo de ley, se sujeta a la responsabilidad penal antes referida; responsabilidad que recae en el gerente o funcionario de más alto nivel; o el titular del pliego (en caso de empleadores que sean entidades públicas).

\subsection{Mecanismos de Justicia Internacional}

El texto de la Convención Interamericana de Derechos Humanos crea en su Capítulo VIII la Corte Interamericana de Derechos Humanos (en adelante, $\mathrm{CIDH}$ ). Esta constituye una instancia internacional que garantiza la protección efectiva de los derechos humanos reconocidos en los Pactos Internacionales de los que los Estados son parte. La Constitución Peruana de 1979 señaló expresamente el reconocimiento a la Comisión Interamericana de Derechos Humanos y la $\mathrm{CIDH}$, precepto que hasta hoy mantiene su vigencia.
En la Constitución Política de 1993, artículo 205, el Perú reitera el reconocimiento de las Cortes Internacionales, señalando expresamente que "Agotada la jurisdicción interna, quien se considera lesionado en los derechos que la constitución reconoce, puede recurrir a los Tribunales uorganismos internacionales constituidos según tratados de los que es parte el Perú".

De esta manera, al ser parte de la Convención de San José y haberse reconocido expresamente la competencia de la CIDH, los ciudadanos peruanos tienen el derecho a recurrir a mecanismos procesales supra-legales internacionales frente al Estado Peruano, en tutela de sus derechos fundamentales, incluyendo el derecho fundamental a la pensión. La disposición constitucional prevé para ello tres requisitos:

a. El agotamiento de la jurisdicción interna. Ello quiere decir que, antes de interponer la acción a nivel supra-nacional, el denunciante deberá haber acudido a los tribunales nacionales en defensa de sus derechos, habiendo agotado todas las instancias judiciales, e incluso constitucionales, previstas por el ordenamiento interno.

b. El segundo requisito hace referencia a un concepto mencionado previamente: la validez de la pretensión. El denunciante deberá ser titular de una acción válidamente fundada en derechos constitucionalmente protegidos; el Derecho a la Pensión.

c. Esta acción debe ampararse en los tratados previamente suscritos por el Perú. El artículo 55 de nuestra Constitución Política ${ }^{26}$ prevé la incorporación automática del contenido de los tratados al ordenamiento interno; ello quiere decir que los tratados que hayan sido debidamente celebrados $-y$ se encuentren

\footnotetext{
25 Estas pretensiones se trasladan como "medida urgente" previo traslado a la otra parte por el plazo de tres días. Vencido el plazo, con o sin absolución de la demanda, el Juez dictará en la sentencia la medida que corresponda a la pretensión invocada dentro del plazo de cinco días.

26 CONSTITUCIÓN POLÍTICA DEL PERÚ.

"Artículo 55.- Los tratados celebrados por el Estado y en vigor forman parte del ordenamiento nacional."
} 
en vigor según las normas internacionales que los rijan- integrarán de manera automática el derecho nacional.

\section{CAPÍTULO 3: ANÁLISIS DE DERECHOS CONSTITUCIONALES QUE PODRÍAN SER AFECTADOS POR UNA SITUACIÓN DEL TIPO ARGENTINO}

Utilizando como marco de análisis los conceptos desarrollados en la sección anterior de esta ponencia, a continuación analizamos qué derechos constitucionales podrían ser vulnerados en caso que se implementase en el Perú una medida respecto del SPP similar a la dada en el caso argentino.

Para efectos del análisis, consideraremos cada derecho constitucional en forma aislada e independiente. En este sentido, por ejemplo, se analizará la posible vulneración del Derecho a la Pensión sin tener en cuenta que la misma actuación gubernamental podría importar una violación del derecho de propiedad, del derecho a contratar, o del derecho al libre acceso a las prestaciones pensionarias.

\section{(a) Derecho a la propiedad y la herencia}

Como se indicó con anterioridad, el régimen económico de la República del Perú es el de una economía social de mercado, en la que se protege el derecho de propiedad como una base fundamental de la organización del sistema económico. En este sentido, si bien existen limitaciones al derecho de propiedad, es claro que el bienestar colectivo no puede ser aprovechado discrecionalmente por los gobiernos para hacerse de la propiedad privada de manera arbitraria. El reconocimiento de la inviolabilidad del derecho de propiedad implica la necesidad de justificar su violación en una causa fundada en la ley (de seguridad nacional o necesidad pública), y el otorgamiento de una indemnización derivada de su afectación.
De acuerdo lo anterior, si el Estado dispusiera la eliminación del SPP, como en el caso argentino, aún basándose en la cautela del interés colectivo, es evidente que se vulneraría el derecho de propiedad. Primero, el derecho de propiedad de los propios fondos privados de pensiones como titulares de los activos que integran sus carteras y que son administrados por las AFP. Pero el análisis también debe hacerse a otro nivel: el derecho de propiedad de los afiliados al SPP.

En este marco, cada afiliado tiene auténticamente propiedad sobre el saldo de su CIC, de manera que la privación de este derecho constituiría una afectación inconstitucional al derecho de propiedad -en rigor, una confiscación- aunque sea reemplazado por otro derecho pensionario. En tal sentido, la eliminación del SPP, al estilo del caso Argentino, implicaría una clara vulneración del derecho de propiedad.

(b) Derecho a la Intangibilidad de los Fondos y Reservas Previsionales

En su acepción coloquial, "intangible" es algo que "no puede o debe tocarse". Para la legislación peruana, que recoge la garantía de intangibilidad de recursos provisionales prevista en la Constitución Política, los fondos de la seguridad social son recursos intangibles. Ello implica, a tenor de la propia Constitución que "los recursos se aplican en la forma (... que señala la ley".

Como se mencionó anteriormente, el concepto de intangibilidad fue desarrollado normativamente en el marco del Decreto Legislativo 817 mediante el cual se creó el FCR, precisándose a nivel reglamentario que "los fondos y reservas previsionales que administra el FCR son intangibles".

Asimismo, las normas aplicables a la ONP27 establecen que "los recursos (de los Sistemas previsionales a cargo de la ONP) son inembargables y sólo pueden ser utilizados para pagar las obligaciones pensionarias, los gastos inherentes al manejo de

27 Reglamento de la Ley que establece la Reestructuración Integral de la ONP, aprobado por Decreto Supremo №. 1082008-MEF. 
sus inversiones y los gastos de administración (del sistema) (el agregado y subrayado son nuestros)". Con esta norma, se amplían los supuestos de aplicación de los recursos previsionales, no solo para atender las obligaciones pensionarias a cargo del Estado sino también los gastos derivados de la administración y gestión del SNP.

La Ley del SPP establece algunas garantías adicionales que permiten que la finalidad pensionaria de los fondos del SPP se cumpla a cabalidad:

(a) Cada fondo de pensiones, es un "patrimonio autónomo" y debe ser constituido como un portafolio de inversiones separado y distinto al (ii) patrimonio de la de AFP lo conduce y opera; $y$, (ii) los otros fondos que integren la cartera de la AFP. Al efecto, la Ley del SPP establece de manera expresa que las AFP deben llevar contabilidad separada y registros de operaciones por cada fondo administrado.

Según lo indicado, los activos de cada fondo que administra una AFP no responden por obligaciones propias de las AFP, ni por obligaciones de otros fondos a cargo de la AFP.

(b) La Ley del SPP establece que los bienes que integran los fondos de aportes obligatorios bajo el SPP y los aportes voluntarios con fin provisional, entre otros, son inembargables (el subrayado es nuestro), por lo que, en principio, los acreedores de los fondos no podrán dirigirse contra los recursos que integran sus carteras.

(c) De acuerdo con la Ley del SPP, el patrimonio del fondo de pensiones y las operaciones que se realicen con cargo a estos, se encuentran inafectas al pago de todo tributo creado o porcrearse, inclusive de aquellos que requieren de norma exoneratoria expresa. Asimismo, se encuentran inafectos al Impuesto a la Renta peruano, los dividendos, intereses, comisionesylas ganancias de capital percibidas por cada fondo de pensiones. Las inafectaciones antes mencionadas se extienden también a cada $\mathrm{ClC}$.
En el caso del SPP, no existe una norma que señale expresamente el carácter intangible de los recursos de los fondos privados de pensiones. ¿Esto quiere decir que los recursos del SPP se encuentran totalmente expuestos a usos distintos a los previsionales? Desde luego que no. Como se ha señalado precedentemente, el SPP es parte del sistema de seguridad social previsto en la Constitución. En consecuencia, es claro que los fondos de pensiones que administran las AFPs tienen el carácter de "fondosy reservas de seguridad social". Su carácter privado y los derechos de propiedad que recaen sobre ellos son por completo independientes y no son contradictorios con lo anterior.

Considerando lo descrito en esta sección, conviene evaluar si una medida de confiscación o nacionalización implicaría una violación del derecho a la intangibilidad de los fondos. Bajo este escenario hipotético, los fondos del SPP serían destinados un fondo común destinado probablemente por ley expresa a "atender obligaciones previsionales", por lo que, al menos nominalmente, se mantendría el "carácter previsional de los fondos de pensiones". Un ejemplo es lo señalado en el artículo 8 de la Ley del SIPA, que señala que "la totalidad de los recursos únicamente podrán ser utilizados para pagos de los beneficios del Sistema Integrado Previsional Argentino (...)".

Si se mantiene y respeta el carácter previsional de los fondos pensionarios, pero por ley se cambia su forma de aplicación dentro de la finalidad previsional, podría eventualmente discutirse la vulneración de la garantía de intangibilidad de los fondos y reservas de seguridad social que establece la Constitución. Sin embargo, en la práctica esa discusión carece de utilidad en el caso de los fondos del SPP por dos razones. En primer lugar, parece remota la posibilidad de que un Gobierno proceda a afectar los fondos privados de pensiones y cambiar su destino sin tener como motivación ulterior el uso de tales recursos para finalidades distintas a la previsional. Y, en segundo lugar, dada la naturaleza del SPP, esta afectación implicaría necesariamente la violación del derecho de propiedad. 


\section{(c) Libertad de Acceso}

Al definir las bases constitucionales del Derecho a la Pensión, se mencionó el reconocimiento del derecho de libre acceso a una pluralidad de regímenes pensionarios a través de entidades públicas, privadas o mixtas. Actualmente, independientemente de regímenes de carácter cerrado (como el ya mencionado régimen de la Ley 20530) o de regímenes privativos para determinados grupos de trabajadores, coexisten como regímenes abiertos; el SNP y el SPP. Por ello, para definir las implicancias de contar con libre acceso al régimen pensionario, resulta conveniente perfilar las principales diferencias que entre los regímenes antes referidos.

El SNP es un régimen abierto, de aportación obligatoria, que posee un fondo intangible y común (bien "de capitalización colectiva" o de "reparto público"), y se encuentra regido, entre otros, por el principio de solidaridad, con lo cual se evidencia su vocación redistributiva.

Pueden incorporarse a este sistema todos los trabajadores dependientes o independientes que no pertenezcan obligatoriamente a un régimen privativo. No obstante, los trabajadores afiliados al SPP pueden hacerlo solo en los supuestos de desafiliación. Entre los requisitos para acceder a pensión de jubilación en el SNP, se encuentran los siguientes: (i) contar con sesenta y cinco (65) años de edad; y, (ii) registrar veinte (20) años de aporte como mínimo. Bajo este sistema, la tasa de aportación es $13 \%$ de la remuneración mensual.

Cabe precisar que este sistema es uno de "beneficio definido por la ley", en el cual, la fórmula para la determinación de las pensiones está establecida en la normativa correspondiente $y$ no depende de la acumulación de ahorros por cada trabajador. Además, el Estado determina los límites mínimos y máximos del monto de la pensión..$^{28}$

Mencionamos ya que el SPP se caracteriza por ser un sistema de propiedad y administración privada, que se enmarca en un régimen de competencia; y se basa en la propiedad privada y la libertad de contratación del individuo. Asimismo, el SPP es una alternativa al SNP; el trabajador tiene la posibilidad de elegir entre cualquiera de los dos regímenes existentes. Sin embargo, cotizar en alguno de ellos es de carácter mandatorio bajo ley peruana.

Al establecerse el SPP se dispuso que los trabajadores incorporados al SNP se encontraban facultados para optar por trasladarse al sistema privado en cualquier momento. Asimismo, se previó que toda trabajador, al momento de ingresar a la masa laboral, debía optar entre el SPP y en SNP. No se estableció, sin embargo, la posibilidad de que los trabajadores ya incorporados al SPP pudieran "desafiliarse" libremente de este para pasar al SNP. En tal sentido, vinculado al tema de la libertad de acceso a los diversos regímenes pensionarios se planteó la discusión constitucional sobre el tema de la libre desafiliación.

Al respecto, cabe precisar que, luego de un largo debate, mediante la Ley 28449 publicada en marzo de 2007, se aprobó la "Ley de libre desafiliación informada, pensiones mínima y complementarias, y régimen especial de jubilación anticipada" (la "Ley de Libre Desafiliación"). ${ }^{29}$

28 Actualmente, el monto mínimo de la pensión es de S/. 415 para los pensionistas de invalidez y jubilación con más de 20 años de aportaciones; y un máximo de S/. 835. Fuente: Memoria Institucional 2007 de la ONP publicada en su página web: www.onp.gob.pe .

29 La Ley de Libre Desafiliación norma establece que los siguientes sujetos están facultados para desafiliarse del SPP y regresar al SNP: (a) los afiliados al SPP que hubiesen ingresado al SNP hasta el 31 de diciembre de 1995, y que al momento de presentar la solicitud de desafiliación cumplen con los años de aportación para tener una pensión de jubilación en el SNP; $y$ (b) todos los afiliados al SPP que, al momento de la afiliación a este sistema privado, cuenten con los requisitos para obtener una pensión de jubilación en el SNP. Sin embargo; la Ley de Libre Desafiliación impide la desafiliación de sujetos que ya fuesen pensionistas del SPP, sin perjuicio de lo cual se ha establecido el pago de una pensión complementaria para igualar la pensión del SPP a la del SNP, en el caso de algunos pensionistas del SPP. 
El objetivo de la norma fue permitir que aquellos trabajadores cuya pensión en el SNP fuese mayor a la que recibirían en el SPP, tengan la posibilidad de retornar voluntariamente al sistema público, en virtud del derecho de libre acceso a la seguridad social consagrado en la Constitución Política. Cabe precisar, que la Ley de Libre Desafiliación establece que el procedimiento de desafiliación no debe contemplar ninguna restricción a la libertad del trabajador para desafiliarse, debiendo proveerse a este de toda la información necesaria para que tome libremente su decisión. ${ }^{30}$

Esta ley tuvo como antecedentes casos de desafiliación ventilados ante el Tribunal Constitucional, en los cuales se ha pronunciado adoptando un criterio según el cual el libre acceso a la pensión incluye la capacidad del ciudadano para trasladarse de un régimen pensionario a otro.

Asimismo, fluye del criterio esbozado por el Tribunal Constitucional que la posibilidad de trasladarse de un régimen a otro implica no solo migrar del SNP al SPP sino también del SPP al SNP, lo cual se derivaría respeto de la "libertad individual de la persona y la libertad de contratación". Al respecto, el Tribunal Constitucional ha señalado que:

"Si pese a considerarse que entre los sistemas pensionarios existen notorias diferencias, $y$ no obstante ello -o a pesar de ello- se posibilitó que una persona que pertenece al SNP pueda trasladarse al SPP, entonces, no hay razón constitucionalmente aceptable para que también libremente, dicho individuo [no] pueda retrotraerse de su decisión originaly, en consecuencia, se le permita el retorno del SPP al SNP".31

El Tribunal Constitucional mencionó hasta tres supuestos en los que debe permitirse el traslado del SPP al SNP: (i) supuesto de "titularidad no ejercida", esto es, cuando se trate de personas que cumplian con requisitos para acceder a una pensión bajo el SNP pero aún así no la reclamaron y accedieron al SPP; (ii) supuesto de falta de información; es decir cuando el acceso al SPP se dio en condiciones donde la persona no fue debidamente informada sobre las ventajas y desventajas de cada sistema, por lo que su voluntad se encuentra viciada; $y$, (iii) trabajadores cuyas condiciones para la vida impliquen un riesgo para la vida o la salud (en particular, este supuesto se daría en la situación de los trabajadores mineros afiliados a las AFP).

Sin perjuicio de lo anterior, debe resaltarse que ha sido criterio adoptado por el Tribunal Constitucional el no promover el retorno absoluto, sino mas bien el retorno parcial o relativo (en supuestos específicos) basado en el hecho que lo primero implicaría un grave perjuicio para las finanzas del Estado, que podría terminar perjudicando a los pensionistas en lugar de beneficiarlos. En efecto, entendemos que al ser el SNP un régimen de capitalización colectiva o de reparto, donde los recursos para el pago de pensiones que benefician a la comunidad, se derivan de aportes de todos los trabajadores y de los aportes estatales, la libre desafiliación absoluta podría implicar una contravención al principio constitucional de sostenibilidad financiera, introducido con ocasión de la reforma constitucional (a partir de la modificación al régimen del Decreto Ley 20530).

Adicionalmente, debe tenerse en cuenta que, según el Tribunal Constitucional la libertad de acceso garantiza que "el Estado no interferirá en la libre decisión que puede tomar la persona para elegir por un sistema o por otro, por más que el Estado se haya decidido a promover su sistema determinado (... $)^{\prime 3 .}$

30 Esto incluye la información sobre el monto de pensión estimado en el SNP y en el SPP, el monto adeudado por el diferencial de aportes y las constancias de haber cumplido con los requisitos de años de aporte para tener una pensión en el régimen pensionario respectivo, certificados por la SBS y la ONP, entre otros.

31 Resolución del Tribunal Constitucional de 26 de enero de 2007; Expediente No. 1776-2004-AA/TC.

32 Ídem. 
A la luz de los criterios sobre libre acceso adoptados por el Tribunal Constitucional, cabe preguntarse si se vulneraría esta libertad de acceso si el Gobierno Peruano dispusiera la eliminación del SPP y la absorción de las CIC por el régimen público.

Entendemos que sí. El texto literal del artículo 11 de la Constitución Política, que garantiza el "libre acceso" a prestaciones de salud y de pensiones a través de entidades públicas, privadas o mixtas, implica a nuestro criterio, el derecho del individuo a la posibilidad de elegir, entre los esquemas pensionarios previstos en la Constitución.

En efecto, no es posible argumentar que el "libre acceso" previsto por la Constitución Política implique para el individuo la libertad de decidir entre acceder o no a prestaciones de salud o pensiones, debido a la naturaleza de los sistemas de seguridad social referidos a salud y pensiones.

En este sentido, la única acepción posible del término libre acceso implica la posibilidad de elegir entre los sistemas que prevé la Constitución. Por ello, una medida gubernamental que elimine el SPP dejando a todos trabajadores peruanos como afiliados obligatorios del SNP constituiría una afectación del derecho al libre acceso previsto en el artículo 11 de la Constitución Política del Perú.

\section{(d) El Derecho a la Pensión}

Como vimos anteriormente, la Constitución Política establece el derecho fundamental de todo ciudadano de gozar del derecho a la seguridad social para la elevación de su nivel de vida $y$, dentro de éste derecho, se reconoce el Derecho a la Pensión.

La pregunta es ¿qué pasaría en el supuesto negado que el Gobierno Peruano dispusiera la eliminación del SPP de manera similar al caso argentino? ¿Se vulneraría el Derecho a la Pensión? Nótese que, desde esta perspectiva, estamos enfatizando al Derecho a la Pensión como un derecho que tiene todo ciudadano a recibir una prestación económica materializada a través de una suma de dinero.

A nuestro criterio, la respuesta no es absoluta, pues el Derecho a la Pensión está conceptualizado en el ordenamiento constitucional peruano como derecho de configuración legal de manera que su aplicación está sujeta al desarrollo de la ley, que completa su contenido y alcance.

Así, por ejemplo, si la ley establece que deben cumplirse determinados requisitos legales en cuanto a la edad para el retiro y el número de aportes a fin de tener derecho a una pensión de jubilación, y posteriormente, esa misma ley es modificada, en la medida que no se afecte derechos adquiridos, no se habría vulnerado el Derecho a la Pensión del ciudadano en cuestión.

Además, el Derecho a la Pensión desde su enfoque en el SNP está sujeto a una serie de políticas públicas como la que orienta la sostenibilidad financiera y equilibrio presupuestario del Estado. Por ello, puede decirse que, el Derecho a la Pensión está limitado por el equilibrio del presupuesto público. De ahí que la Undécima Disposición Transitoria y Final de la Constitución Política mencione que "Las disposiciones de la Constitución que exijan nuevos o mayores gastos públicos se aplican progresivamente".

Entonces, de acuerdo a lo anteriormente expuesto, si el Derecho a la Pensión es un derecho de "configuración legal", mal podría sostenerse que este derecho se vulneraría strictu sensu si por el solo hecho de que, mediante la expedición de una ley, se elimine el SPP y se transfiera la prestación pensionaria al SNP.

Ahora bien, lo antes dicho procederá en tanto y en cuanto no se afecte "derechos adquiridos". Este concepto, deriva de la teoría de los vested rights, desarrollada a partir del célebre caso Calder vs. Bull por el juez Chase en 1798 como un método de control de constitucionalidad para proteger particularmente, los derechos de

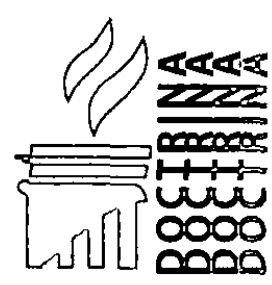


propiedad e igualdad frente a leyes retroactivas emanadas de la autoridad legislativa. ${ }^{33}$

Lo que propugna la teoría de los derechos adquiridos es que "la norma bajo la cual nació determinado derecho, continúa rigiéndolo mientras tal derecho surta efecto aunque en el trayecto dicha norma sea derogada o sustituida" ${ }^{34}$ Bajo esta teoría, se otorgaría estabilidad normativa al derecho adquirido, al amparo del principio constitucionalmente consagrado de irretroactividad de las leyes (artículo 103 de la Constitución Política): "Ninguna ley tiene fuerza ni efecto retroactivo, salvo en materia penal, cuando favorece al reo".

El Tribunal Constitucional ha tenido ocasión para pronunciarse sobre los derechos adquiridos en materia pensionaría como "aquellos derechos que han entrado en nuestro dominio, que hacen parte de él, y de los cuales ya nadie puede privarnos [ni] aquél de quien los tenemos.".35

De acuerdo a este criterio, si al amparo de una ley dada, un ciudadano había cumplido con los requisitos para acceder a una pensión, y en consecuencia, había ingresado legalmente a su patrimonio el derecho en cuestión, se afectarían sus derechos adquiridos a dicha pensión, si posteriormente se establecieran requisitos distintos o adicionales a los ya cumplidos bajo la normativa anterior, para gozar de ella, que tengan el efecto de privarlo del "derecho adquirido".

Sin perjuicio de lo anteriormente indicado, debe resaltarse que el concepto de derechos adquiridos fue interpretado y desarrollado por el Tribunal Constitucional principalmente en casos basados en la aplicación de la Primera Disposición Final y Transitoria de la Constitución Política de 1993 (antes de su reforma constitucional en el 2004) que establecía que "Los nuevos regímenes sociales obligatorios, que sobre materia de pensiones de los trabajadores públicos, seestablezcan, no afectan los derechos legalmente obtenidos, en particular el correspondiente a los regímenes de los Decretos Leyes 19990 y 20530 y sus modificatorias. (el subrayado es nuestro)". Esta protección de los derechos adquiridos impedía en la práctica cualquier intento por fijar topes o condiciones distintas para el régimen del Decreto Ley 20530.36

En abril de 2004, el Poder Ejecutivo presentó ante el Congreso un proyecto para modificar, entre otras, la Primera Disposición Final y Transitoria de la Constitución Política de 1993, dando lugar a la Ley 28389, la cual (i) declaró cerrado definitivamente el régimen pensionario de los funcionarios públicos regulado por el Decreto Ley 20530; (ii) prohibió las nuevas incorporaciones o reincorporaciones a dicho régimen pensionario; (iii) estableció que los trabajadores adscritos a dicho régimen que no hubieran cumplido con los requisitos para obtener la pensión correspondiente a la fecha de la reforma, debían optar por el SPP o el SNP; (iv) prohibió la nivelación de pensiones con las remuneraciones; (v) dispuso la aplicación progresiva de topes a las pensiones, entre otras reglas que privilegian los criterios de sostenibilidad financiera del Estado y no nivelación.

De otro lado, debemos destacar que el derecho a la pensión se encuentra integrado en el derecho de propiedad, desde que este último constituye un derecho patrimonial integrado por un haz de facultades, bienes y derechos materiales e inmateriales. Además de encontrar protección a nivel constitucional, el derecho de propiedad

33 LINARES, Juan Francisco, La Razonabilidad de las leyes, El debido proceso como garantía innominada en la Constitución Argentina, Editorial Astrea, Segunda Edición, Buenos Aires, 1989, pp. 63 - 65

34 RUBIO CORREA, Marcial, Para leer el Código Civil: Título Preliminar, Volumen III, Fondo Editorial de la Pontificia Universidad Católica del Perú, Lima, 2001, pp. 58 - 59.

35 STC de 23 de abril de 1997, recaída sobre el Expediente No. 008-96-1/TC.

36 Cabe agregar que, el régimen del Decreto Ley 20530 representó un gasto sustancial para el Estado Peruano en cuanto su mantenimiento y además, mediante diversas normas reglamentarias se permitió el ingreso irregular e indiscriminado a muchos trabajadores a quien no correspondia beneficiarse de sus prestaciones. 
tiene reconocimiento en sede internacional. Al respecto, el artículo 21 de la Convención Interamericana de Derechos Humanos, del cual Perú es signatario, establece:

"Artículo 21. Derecho a la Propiedad Privada

1. Toda persona tiene derecho al uso y goce de sus bienes. La ley puede subordinar tal uso y goce al interés social.

2. Ninguna persona puede ser privada de sus bienes, excepto mediante el pago de indemnización justa, por razones de utilidad pública o de interés socialy en los caos y según las formas establecidas porla ley.

3. Tanto la usura como cualquier otra forma de explotación del hombre por el hombre, deben ser prohibidas por la ley" (e) subrayado es nuestro).

En la línea de lo expuesto, el Derecho a la Pensión como derecho patrimonial de los afiliados encuentra su fundamento en el derecho de la propiedad, por lo que cualquier medida de confiscación similar al tipo argentino que no respete las garantías previstas en la Constitución carece de legitimidad. Adicionalmente, cabe indicar que resulta difícil imaginar un supuesto en el que la afectación de la propiedad de los fondos de pensiones por parte de los trabajadores afiliados a las AFP pudiera ser fundamentada bajo el ordenamiento constitucional peruano, en la medida que tal afectación tendría que darse bajo estrictos requisitos aplicables a la expropiación.

Cabe indicar, finalmente, que en virtud a su carácter multiplicador, el derecho de propiedad comprende también derechos de naturaleza crediticia como el Derecho a la Pensión.
Sobre el particular, la Corte Interamericana de Derechos Humanos (Caso Cinco Pensionistas vs. Perú) ${ }^{37}$ se pronunció entendiendo que la afectación del Derecho a la Pensión es una afectación directa al derecho de propiedad. En tal sentido concluyó que la reducción de pensiones que no se base en una decisión estatal fundamentada en razones de utilidad pública o interés social, ni en criterios de razonabilidad, constituye una confiscación ilegitima e indebida del patrimonio de los pensionistas, en su calidad de acreedores y propietarios de la pensión de jubilación; y en consecuencia, encontró responsabilidad en el Estado de la República del Perú derivada de la violación del Artículo 21 de la Convención de Derechos Humanos que garantiza el Derecho a la Propiedad Privada.

\section{CAPÍTULO 4: LA EXPROPIACIÓN INDI- RECTA Y LA PROTECCIÓN DE LA PRO- PIEDAD EN LOS TRATADOS INTERNA- CIONALES}

A diferencia de la confiscación o expropiación que suponen la transferencia forzosa del derecho a la propiedad privada a favor del Estado justificada en el interés público, la expropiación indirecta puede definirse como"aquella medida estatal que formalmente no constituye una expropiación de la propiedad por el Estado pero lesiona al derecho de la propiedad o a sus atributos de manera tal que le resta todo o parte de su valor".38

Ello puede llevarse a cabo a través del sistema de tributación, o a través de medidas regulatorias que limiten la posibilidad de obtener una rentabilidad razonablemente esperada. Tal sería el caso, por ejemplo, en el que se obliga a los fondos de pensiones a adquirir determinados instrumentos de inversión en condiciones des-

37 Caso "Cinco Pensionistas vs. Perú" Sentencia de 28 de febrero de 2003, donde se discutió, entre otros, la posibilidad de aplicar topes a las pensiones de cinco ex trabajadores de la Superintendencia de Banca y Seguros, sujetos al régimen del Decreto Ley 20530 (el que permitía la nivelación de pensiones de funcionarios públicos en función de los trabajadores en actividad) con posterioridad al cumplimiento por parte de estos ex trabajadores de los requisitos legales necesarios para adquirir el Derecho a la Pensión bajo el régimen antes mencionado.

38 AMADO, Daniel y AMIEL, Bruno, La Expropiación Indirecta y la Protección de Inversiones Extranjeras. En: Revista Themis No. 50, Lima, 2005, p. 60. 
favorables y/o se obliga a convertir a moneda local, instrumentos nominados en moneda extranjera a un tipo de cambio menor al vigente.

A nivel de derecho interno, la protección de la propiedad privada frente a las medidas de expropiación tiene su base en la Constitución, además de contarse con respaldo en la Ley de Expropiación 27117 que contiene un procedjmiento de expropiación expresamente regulado. Adicionalmente, el Decreto Legislativo 662, el Decreto Legislativo 757 y el Decreto Supremo No. 162-92-EF otorgan a los inversionistas extranjeros, protecciones frente a la expropiación. Sin embargo, la legislación interna no regula de manera expresa los casos de medidas estatales que tienen un efecto análogo a la confiscación de la propiedad: los casos de expropiación indirecta.

La protección frente a la expropiación indirecta se encuentra regulada básicamente a nivel del Derecho Internacional. Sobre el particular, el Restatement (Third) of the Foreign Relations Law, se refiere a la responsabilidad del Estado derivada de (a) una toma de la propiedad para una finalidad distinta a la pública, discriminatoria; o que no se encuentra acompañada por una compensación justa; (b) un incumplimiento contractual del Estado, siempre que sea discriminatorio, injustificado y no resarcido; o que no haya sido materia de un procedimiento adecuado para su oposición o de compensación por el incumplimiento ${ }^{39}$; $y$, (c) cualquier otra acción gubernamental de efecto similar a una toma de propiedad como las medidas tributarias, regulatorias o cualquier otra acción confiscatoria, que impida, interfiera, o que demore irrazonablemente, el goce del derecho de propiedad o su disposición dentro de un territorio (traducción libre). ${ }^{40}$

Ahora bien, el Perú ha participado y es parte de un gran número de Bilateral Investment Treaties (BIT) o tratados bilaterales de inversión; así como en acuerdos de libre comercio (ALC) los cuales proveen de ciertas medidas de protección frente a la expropiación indirecta a los inversionistas.

Así se tiene, por ejemplo, el TLC del Perú con los Estados Unidos de Norteamérica, en cuyo Capítulo 10 de Inversiones se da un reconocimiento reciproco favor de los inversionistas de los Estados Parte de diversos derechos sustantivos como son las garantías relacionadas con las expropiaciones.

El artículo 10.7 del Capítulo 10 del TLC con los Estados Unidos de Norteamérica establece lo siguiente:

"Artículo 10.7: Expropiación e Indemnización: 1. Ninguna de las Partes puede expropiar ni nacionalizar una inversión cubierta, sea directa o indirectamente mediante medidas equivalentes a la expropiación o nacionalización ("expropiación"), salvo que sea:

(a) por motivos de propósito público;

(b) de una manera no discriminatoria;

(c) mediante el pago pronto, adecuado y efectivo de la indemnización; $y$

39 "A state is responsible under international law for injury resulting from:

(1) a taking by the state of the property of a national of another state that ( $a$ ) is not for a public purpose or (b) is discriminatory, or (c) is not accompanied by a provision for a just compensation;

(2) a repudiation or breach by the state of a contract with a national of another state (a) where the repudiation or brea$\mathrm{ch}$ is (i) discriminatory; or (ii) is motivated by non commercial considerations and compensatory damages are not paid; or (b) where foreign national is not given an adequate forum to determine his claim of repudiation or breach, or is not compensated for any repudiation or breach determined to have occurred".

40 "This [principle] applies not only to avowed expropriation in which the government formally takes property, but also to other actions of the government that have the effect of taking the property in whole or large part, outright or in stages. The state is responsible for foreign expropriation of property under [this principle] when it subjects alien property to taxation, regulation or other action that is confiscatory, or that prevents, unreasonably interferes with or unduly delays, effective enjoyment of an alien's property or it removal from the state's territory". 
(d) con apego al principio del debido proceso y al Artículo 10.5." (el subrayado es nuestro).

Asimismo, dispone algunos requisitos para e! pago de la indemnización antes referida, señalando que debe ser pagada sin demora y a valor "justo de mercado"; debiendo ser completamente liquidable y libremente transferible.

De acuerdo a lo anterior, y según lo previsto en el Anexo 10-B del TLC con los Estados Unidos, la expropiación indirecta es un acto o serie de actos que tienen el efecto equivalente al de una expropiación sin la transferencia formal de la propiedad.

Por su parte, de manera similar a lo dispuesto en el TLC con los Estados Unidos, el artículo 812 del TLC con Canadá establece lo siguiente:

\section{"Articulo 812: Expropiación}

1. Ninguna de las Partes podrá nacionalizar o expropiar una inversión cubjerta, sea directa $\underline{0}$ indirectamente, mediante medidas que tengan un efecto equivalente a la nacionalización o expropiación (en adelante "expropiación"), salvo por propósito público, de conformidad con el debido proceso, de una manera no discriminatoria y mediante una indemnización pronta, adecuada y efectiva", (el subrayado es nuestro).

En este caso también se indica que la indemnización debe ser por lo menos equivalente al valor justo de mercado de la inversión expropiada inmediatamente antes de que la expropiación se hubiera llevado a cabo.

Dicho esto, corresponde evaluar cuándo una medida del gobierno podría tener un efecto "similar o análogo a una expropiación" sin existir propiamente una detracción de la propiedad privada, para lo cual el Anexo - B del TLC con los Estados Unidos, nos proporciona algún alcance.

Sobre el particular, menciona que debe verificarse caso por caso, precisando que debe considerarse: (i) el impacto económico del acto gubernamental; (ii) la posibilidad de interferen- cia con las expectativas inequivocas y razonables de la inversión; (iii) el carácter de la acción gubernamental; $y$ (iv) su justificación; si se funda en razones del bienestar público (tales como la salud pública, la seguridad y el medioambiente), por lo que una medida estatal que obligue a los fondos a adquirir forzosamente títulos públicos o limite o restrinja las inversiones de las AFP, en forma tal que afecte la posibilidad real de las empresas de desarrollar sus actividades y negocios, podría ser considerada una medida de expropiación indirecta en lo términos de los acuerdos comerciales antes mencionados.

\section{CAPÍTULO 5: CONCLUSIONES Y RECOMENDACIONES}

Luego de haber analizado en los capítulos anteriores cómo el derecho de propiedad se encuentra estrechamente vinculado al derecho a la seguridad social y en la medida que ambos son considerados como derechos fundamentales con sustento constitucional, entendemos que los fondos del SPP y los afiliados al SPP cuentan con mecanismos sustantivos y procesales válidos -previstos en el ordenamiento jurídico peruano- para revertir una medida del tipo argentino. Sin perjuicio de ello, es claro que el riesgo de confiscación y/o expropiación indirecta no puede desaparecer completamente dado que es una medida, como advertimos, política y no legal.

En caso que una medida de confiscación del gobierno dispusiera la eliminación del SPP (de la propiedad de los fondos de pensiones sobre las inversiones y del afiliado sobre su (IC), se debe tener presente lo siguiente:

- Se afectaría el derecho de propiedad de los fondos de pensiones sobre sus activos y el de los afiliados sobre si CIC.

- Entendemos que, salvo los"derechos adquiridos" no se afectaría el Derecho a la Pensión en sentido estricto, ya que éste se configura por ley, es decir, su delimitación final depende lo establecido en una norma legal y otros principios aplicables en materia previsional. En este caso, los requisitos para obtener la

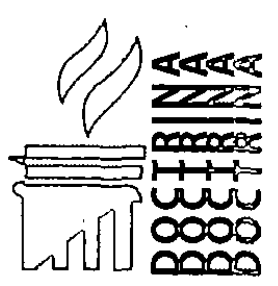

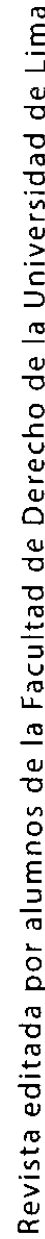

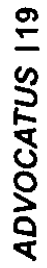


pensión dependerán de lo establecido en la ley.

- Se afectaría el derecho al libre acceso a prestaciones de pensiones al pretenderse que éstos se constituyan en afiliados obligatorios del SNP. Ello en la medida en que la Constitución Política garantiza el derecho de elección entre regímenes provisionales previstos constitucionalmente.

- De acuerdo al criterio esbozado por la Corte Interamericana de Derechos Humanos (Caso Cinco Pensionistas vs. Perú), el derecho a la pensión es una manifestación del derecho a la propiedad. A este nivel, una medida del tipo argentino afectaría el derecho de propiedad de los afiliados al SPP. Sin perjuicio de lo anterior, entendemos que afectaría también el derecho de los propios fondos del SPP.

- Finalmente, implicaría una contravención a la protección constitucional de intangibilidad previsional. Aún cuando la medida fuese legitimada e implementada por una ley, como fue el caso de la Ley del SIPA, los fondos del SPP serían destinados finalmente a atender las necesidades de la caja fiscal. 